\title{
Pour en lire plus : D'un monde à l'autre. Le temps des consciences.
}

André Beauchamp

\section{OpenEdition}

1 Journals

Édition électronique

URL : https://journals.openedition.org/ere/8383

ISSN : 2561-2271

Éditeur

Centr'ERE

Référence électronique

André Beauchamp, "Pour en lire plus : D'un monde à l'autre. Le temps des consciences. ». Éducation relative à l'environnement [En ligne], Volume 17-1 | 2022, mis en ligne le 27 janvier 2022, consulté le 02 février 2022. URL : http://journals.openedition.org/ere/8383

Ce document a été généré automatiquement le 2 février 2022

La revue Éducation relative à l'environnement est mise à disposition selon les termes de la Licence Creative Commons Attribution - Pas d'Utilisation Commerciale 4.0 International. 


\section{Pour en lire plus : D'un monde à l'autre. Le temps des consciences.}

André Beauchamp

\section{RÉFÉRENCE}

Nicolas Huot et Frédéric Lenoir (2020). D'un monde à l'autre. Le temps des consciences. Paris : Fayard, 426 pages

NICOLAS FRÉDÉRIC

HULOT LENOIR

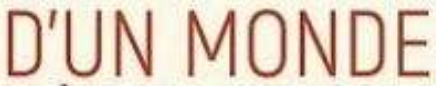

A L'AUTRE

LE TEMPS DES CONSCIENCES

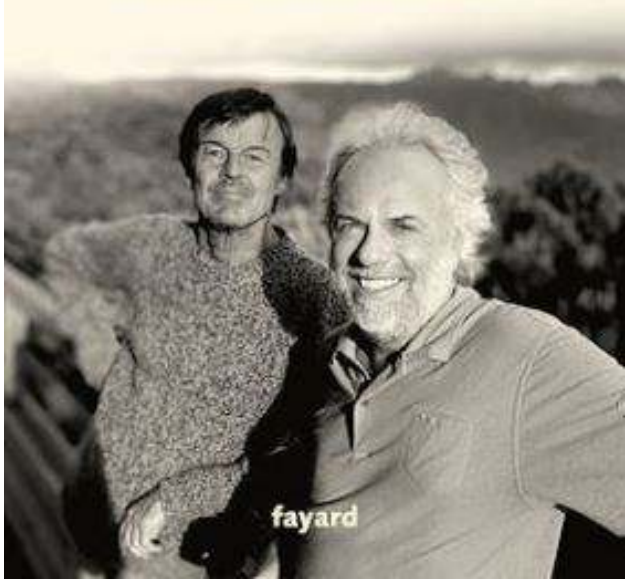


1 Les deux auteurs sont bien connus. Nicolas Huot (né en 1955) a d'abord fait carrière comme journaliste, animateur et réalisateur d'émissions de télévision, notamment USHUAÏA. Son intérêt pour l'environnement se confirme et fait de lui une figure de proue en ce domaine. En 2017, sous la présidence d'Emmanuel Macron, il devient ministre de la Transition écologique et solidaire, mais démissionne quinze mois plus tard et annonce son retrait de la vie politique. Il se consacrera désormais à la cause écologique. Ses propos sur l'écologie, souvent colorés et anecdotiques, sont toujours pertinents.

2 Frédéric Lenoir (né en 1962) est également un personnage très médiatisé. On le présente comme sociologue, philosophe, écrivain, journaliste et conférencier. De 2004 à 2013, il dirige la revue Le monde des religions. Auteur à succès, vulgarisateur des grands philosophes, Frédéric Lenoir s'intéresse beaucoup à la spiritualité, au bonheur, au bienêtre, à la méditation. Et à l'environnement !

Le livre D'un monde à l'autre est la transcription révisée de conversations qu'ont tenues Nicolas Huot et Frédéric Lenoir pendant plus de deux ans. Julie Klotz a fait la transcription des propos. Le résultat donne un livre éclairant, facile à lire, où sont abordés les principaux défis de notre temps. Ce n'est pas révolutionnaire, mais stimulant et instructif. Frédéric Lenoir en profite pour déployer son savoir philosophique et Nicolas Huot rappelle ses aventures et sa conviction écologique. Le sous-titre « Le temps des consciences » est assez exact.

L'échange porte sur neuf thèmes :

- Quel progrès?

- Tout est question de désir ;

- Le règne de l'argent ;

- Les limites du politique ;

- De l'intérêt individuel au bien commun ;

- Mirage du virtuel, éloge du réel ;

- Du toujours plus au mieux-être ;

- Concilier l'unité et la diversité ;

- Donner du sens.

De fil en aiguille, les auteurs parlent d'à peu près tout, de l'environnement, du capitalisme exacerbé, du bonheur, de la beauté, des valeurs à promouvoir, de la laïcité.

Trois chapitres m'ont particulièrement intéressé. Le chapitre trois porte sur le règne de l'argent et la dérive folle du désir de posséder et de consommer qui engendre des impacts sur l'environnement d'une part et sur la société d'autre part. Le chapitre quatre, qui traite des limites de la politique, est remarquable. Il fait presque cent pages et montre bien comment le ministre de l'Environnement (dans le cas de Hulot, ministre de la Transition écologique et solidaire) est au fond, par le jeu des forces politiques, le pantin de ses collègues et le faire-valoir d'innombrables concessions. J'ai également apprécié le chapitre six, celui-là le plus court du livre, sur la tension entre le virtuel et le réel, thème incontournable pour les jeunes d'aujourd'hui.

Pour les personnes impliquées dans l'éducation relative à l'environnement, les points d'ancrage sont nombreux, soit sur le plan proprement écologique (avec les réflexions sur l'argent, le rapport à l'animal, le virtuel, l'agriculture) où des extraits pourraient servir de point de départ à des échanges, soit sur le plan fondamental des motivations et des valeurs. La question du sens et de l'éthique est constamment évoquée. «La 
technologie a bouleversé notre rapport au monde. Ce changement extrêmement important affecte nos modes de vie et de pensée, alors que les grands récits religieux qui ont structuré nos civilisations d'effondrent. Ces bouleversements conduisent à une révolution des consciences. » (Lenoir, p. 346)

8 Frédéric Lenoir insiste à plusieurs reprises sur l'opportunité d'ateliers de philo pour les enfants. Il raconte un événement délicieux. «Lors d'un atelier de philo que j'ai animé quinze jours après les attentats du Bataclan avec des enfants parisiens (...), j'ai été bouleversé par leurs réactions. Je leur avais posé cette question: C'est quoi réussir sa vie ? Le bonheur leur semblait un bon critère d'une vie réussie jusqu'à ce qu'un enfant dise : Je ne suis pas d'accord avec vous, car les terroristes qui ont tué des gens sont heureux de l'avoir fait à cause de leurs croyances. Je ne peux pas dire qu'ils ont réussi leur vie. Pour moi réussir sa vie, c'est être heureux sans avoir fait de mal aux autres, en les ayant respectés. Il a convaincu toute la classe (...) Je me suis alors tourné vers ce petit garçon qui a introduit cette notion de "vie bonne" : Tu vois, il y a un penseur qui a vécu il y a $2500 \mathrm{ans}$, du nom de Socrate, qui a dit la même chose que toi. Ce à quoi il m'a répondu: Je suis heureux de savoir que Socrate pense comme moi ». (p. 260)

9 Sur les valeurs à promouvoir, Hulot et Lenoir s'entendent sur la beauté, la solidarité incluant la compassion, la fraternité, la liberté, le pardon (p. 356 - 408). Le récit se termine par la narration de deux rencontres émouvantes, l'une de Hulot avec Nelson Mandela et une autre de Lenoir avec le Dalaï-Lama.

10 Au bilan, il s'agit d'un livre très axé sur l'urgence de modifier les consciences, éclairant sur la crise écologique, qui insiste sur la nécessité de changer radicalement nos façons de vivre et de penser.

Nous essayons de modifier nos habitudes de penser et nos modes de vie pour participer à l'édification d'une nouvelle civilisation, fondée sur le respect d'autrui et de la nature. Comme beaucoup, nous rêvons d'un monde meilleur et nous refusons de baisser les bras: malgré la puissance des lobbies économiques et le manque de volonté politique, il n'y a aucune fatalité. Nous pouvons être les acteurs du changement vers cet autre monde (p. 413).

\section{AUTEUR}

\section{ANDRÉ BEAUCHAMP}

Théologien, écologiste et consultant en environnement. 